\title{
Greenhouse and field evaluation of transgenic poplars with modified gibberellin metabolism and signaling genes
}

Venkatesh Viswanath ${ }^{1 *}$, Cathleen Ma', Elizabeth Etherington ${ }^{1}$, Palitha Dharmawardhana ${ }^{2}$, David W Pearce ${ }^{3}$, Stewart B Rood ${ }^{4}$, Victor B Busov ${ }^{5}$, Steven H Strauss ${ }^{1}$

From IUFRO Tree Biotechnology Conference 2011: From Genomes to Integration and Delivery Arraial d Ajuda, Bahia, Brazil. 26 June - 2 July 2011

\section{Summary}

Although there have been many observations of transgenes leading to improved plant growth in greenhouse experiments, there is a paucity of data that have been validated by multiple greenhouse experiments or field studies. Genes that encode regulators of gibberellin metabolic pathways were among the first reported to improve biomass growth in trees, and thus were the logical focus of this study. Poplars were transformed with eight different transgenic constructs designed to modify gibberellin biosynthesis and/or signaling. Dramatic improvements in growth rate were observed for several constructs under greenhouse conditions. However, these were often not seen in repeated greenhouse studies, and were statistically unconfirmed for most constructs in the field. Our results underline the importance of multiple greenhouse and field trials during studies with transgenes that modify hormonal homeostasis.

\section{Genes studied}

The genes under investigation in this study were GA20oxidase, PHOR1-1, and SPINDLY. GA20-oxidase catalyzes the conversion of $\mathrm{C}_{20}$-gibberellins to $\mathrm{C}_{19}$-gibberellins through a series of sequential oxidation steps using 2-oxoglutarate as a co- substrate [1]. This enzyme was first isolated from pumpkin cotyledons [2], and is involved in the penultimate step in the production of bioactive gibberellins. The PHOR1-1 gene is a positive regulator that was first isolated from leaves of potato plants subjected to a short day photoperiod (SD) [3].

\footnotetext{
* Correspondence: Venkatesh.Viswanath@oregonstate.edu

'Department of Forest Ecosystems and Society, Oregon State University, 321 Richardson Hall, Corvallis, OR 97331, USA

Full list of author information is available at the end of the article
}

Altered feedback regulation was observed in transgenic plants produced by antisense inhibition of this gene, indicating the role of the PHOR1-1 protein as an intermediate in the gibberellin signaling pathway. SPINDLY $(S P Y)$ is a gene that codes for an O-linked $\mathrm{N}$-acetylglucosamine transferase [4]. In Arabidopsis, it has been shown to inhibit GA signaling, and thus is considered a negative regulator of GA signaling [5].

\section{Methods}

Combinations of the three different genes and seven different promoters were used (Table 1).

In addition to constitutive promoters, we used native promoters of poplar genes which were identified by screening whole-genome microarray expression data. Plants transformed with all eight constructs were grown in the greenhouse, while those transformed with six of these constructs were also grown in the field. For four constructs, the greenhouse trials were repeated at least once. In all, 2,066 trees were studied in the greenhouse (286 independent transformations) and 556 trees (94 independent transformations) were studied in the field. Transgenic and non-transgenic controls were included in both the greenhouse and field studies. Height and diameter measurements were recorded in both the greenhouse and the field, and shoot and root biomass were measured on the greenhouse-grown plants. Levels of bioactive gibberellins were also measured on a subset of plants transformed with the two cisgenes (a gene having driven by its own promoter and ending with its own terminator), as well as in plants that had the RGL and the GA2-oxidase promoters driving the PtGA20-oxidase gene. 
Table 1 Summary of constructs used in the transformation experiments

\begin{tabular}{|c|c|c|c|c|}
\hline Promoter & Gene & Terminator & Number of events studied (GH/Field) & Total number of trees (GH/Field) \\
\hline PtGA200x7 & PtGA200x7 & PtGA20ox7 & $38 / 35$ & $345 / 278$ \\
\hline PtPHOR1 & PtPHOR1 & PtPHOR1 & $26 / 3$ & $327 / 24$ \\
\hline RGL1-1 & PtGA20ox2-2 & NOS & $34 / 17$ & $444 / 83$ \\
\hline GA20x1 & PtGA200x2-2 & NOS & $30 / 15$ & $425 / 75$ \\
\hline B-expansin & PtGA20ox2-2 & NOS & $24 / 0$ & $120 / 0$ \\
\hline PtCESA1 & PtGA200×2-2 & NOS & $16 / 0$ & $80 / 0$ \\
\hline $35 S$ & AtSPY & OCS & $33 / 12$ & $163 / 48$ \\
\hline $35 S$ & HVSPY & OCS & $33 / 12$ & $162 / 48$ \\
\hline
\end{tabular}

\section{Results and discussion}

When considering the best growth rate improvements for constructs that had repeated greenhouse trials, the maximum growth rate improvement seen (the mean of the best two events relative to the control) varied from 50 to $220 \%$ i.e., a fractional growth rate improvement ranging from 0.5 to 2.2 (Figure 1 ).

However, results were not consistent between the different greenhouse trials. The best events showed more than $100 \%$ in maximum growth rate improvement (fractional growth rate improvement $>1$ ) in six different greenhouse experiments (Fig. 1); however, these events did not have a similar extent of improvement when the experiments were repeated. Five out of eight constructs produced a statistically significant improvement in growth rate (Figure 1).

Only one out of the six constructs tested in the field produced a statistically significant improvement in volume index, and this was for the RGL promoter driving the PtGA20-oxidase gene. The GA20-oxidase and the PHOR1 cisgenic plants, when grown in the greenhouse, had substantial increases (73-133\%) in the levels of bioactive gibberellins in developing shoots compared to control plants, however, there was no significant correlation between gibberellin levels and volume index of each event. The levels of the gibberellin biosynthetic precursors were also measured and found to be greater than the bioactive gibberellin level, suggesting feedback inhibition-a possible mechanism for the lack of association with growth. Our results suggest that physiology-modifying transgenes strongly interact with growth environments. This implies that, as in conventional plant breeding, greenhouse results are of limited value and field trials are essential for evaluation of varieties with improved productivity.

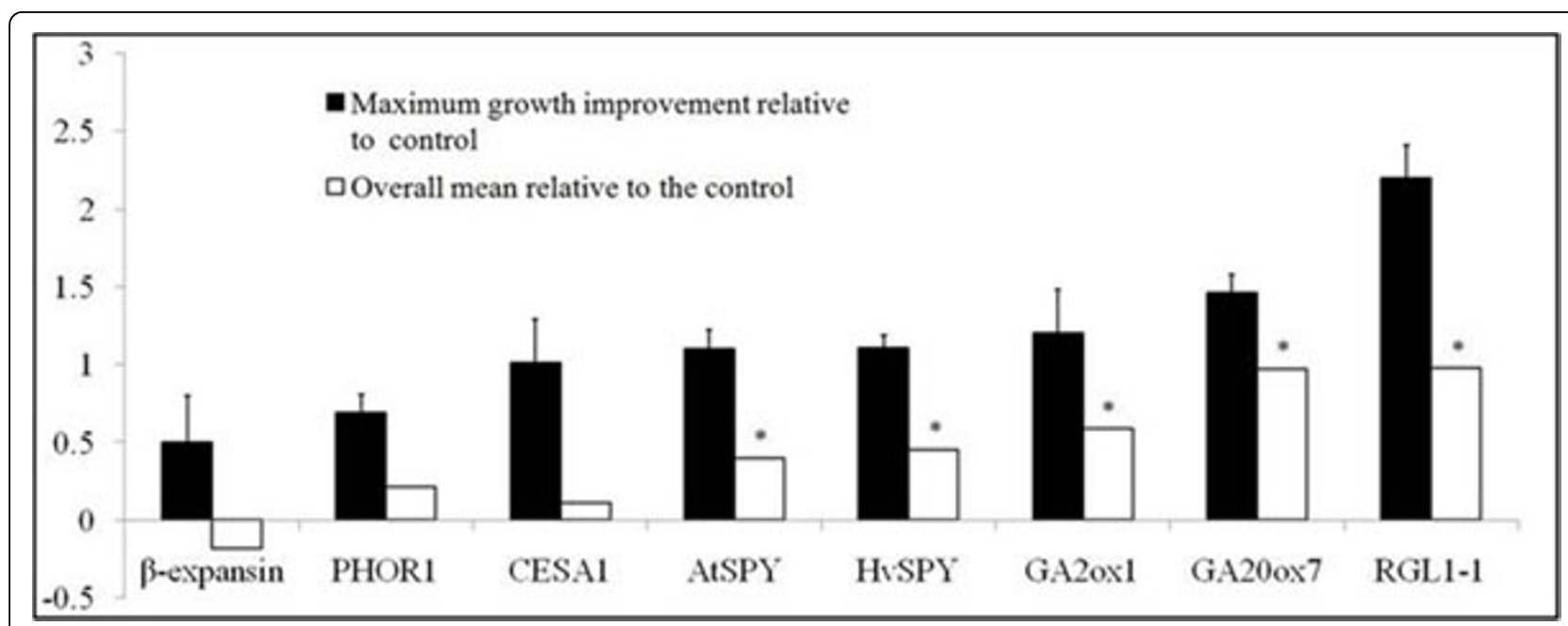

Figure 1 Results from greenhouse trials of transgenic plants. The constructs are denoted by the promoter used, except in the case of SPY genes. Dark bars show the maximum fractional rate improvement (best two transgenic events from best greenhouse experiment) compared to controls. Open bars show the mean fractional growth rate improvement for all transgenic events in that greenhose experiment. Brackets denote one standard error. A "*" above an open bar indicates statistically significant difference between the transgenic and control groups. 


\section{Author details}

${ }^{1}$ Department of Forest Ecosystems and Society, Oregon State University, 321 Richardson Hall, Corvallis, OR 97331, USA. ${ }^{2}$ Department of Botany and Plant Pathology, Oregon State University, 2082 Cordley Hall, Corvallis, OR 97331, USA. ${ }^{3}$ Department of Biological Sciences, University of Lethbridge, 4401 University Dr. W, Lethbridge, AB T1K 3M4, Canada. ${ }^{4}$ Department of Biological Sciences, University of Lethbridge, 4401 University Dr. W, Lethbridge, AB T1K 3M4, Canada. ${ }^{5}$ School of Forest Resources and Environmental Science, Forestry and Wood Products Building, Michigan Technological University, 1400 Townsend Dr. Houghton, MI 49931, USA.

Published: 13 September 2011

\section{References}

1. Yamaguchi S: Gibberellin metabolism and its regulation. Annu Rev Plant Biol 2008, 59:225-251.

2. Lange T, Hedden P, Graebe JE: Expression cloning of a gibberellin 20 oxidase, a multifunctional enzyme involved in gibberellin biosynthesis. Proc Natl Acad Sci U S A 1994, 91:8552-8556.

3. Amador V, Monte E, García-Martínez JL, Prat S: Gibberellins signal nuclear import of PHOR1, a photoperiod-responsive protein with homology to Drosophila armadillo. Cell 2001, 106:343-354.

4. Silverstone AL, Tseng TS, Swain SM, Dill A, Jeong SY, Olszewski NE, Sun TP. Functional analysis of SPINDLY in gibberellin signaling in Arabidopsis. Plant Physiol 2007, 143:987-1000.

5. Greenboim-Wainberg Y, Maymon I, Borochov R, Alvarez J, Olszewski N, Ori N, Eshed Y, Weiss D: Cross talk between gibberellin and cytokinin: the Arabidopsis GA response inhibitor SPINDLY plays a positive role in cytokinin signaling. Plant Cell 2005, 17:92-102.

doi:10.1186/1753-6561-5-S7-O22

Cite this article as: Viswanath et al:: Greenhouse and field evaluation of transgenic poplars with modified gibberellin metabolism and signaling genes. BMC Proceedings 2011 5(Suppl 7):O22.

\section{Submit your next manuscript to BioMed Central and take full advantage of:}

- Convenient online submission

- Thorough peer review

- No space constraints or color figure charges

- Immediate publication on acceptance

- Inclusion in PubMed, CAS, Scopus and Google Scholar

- Research which is freely available for redistribution

Submit your manuscript at www.biomedcentral.com/submit 